\title{
Integrating arsenic in water safety planning in The Netherlands
}

\author{
P. van der Wens ${ }^{1} \&$ A. Ahmad ${ }^{2,3,4}$ \\ ${ }^{1}$ Brabant Water, Department of Drinking Water Production, Breda, The Netherlands \\ ${ }^{2}$ KTH-International Groundwater Arsenic Research Group, Department of Sustainable Development, \\ Environmental Science and Engineering, KTH Royal Institute of Technology, Stockholm, Sweden \\ ${ }^{3}$ KWR Watercycle Research Institute, Nieuwegein, The Netherlands \\ ${ }^{4}$ Department of Environmental Technology, Wageningen University and Research (WUR), Wageningen, \\ The Netherlands
}

\begin{abstract}
The Dutch drinking water sector complies with the most restrictive guidelines in the world and has a long-standing history of striving for excellence in water quality standards. The Dutch Association of Drinking Water Companies (Vewin) concluded in 2015 to lower the standard on arsenic in drinking water to $1 \mu \mathrm{g} \mathrm{L}-1$. Following the new recommendation Brabant Water, a major water supply company in The Netherlands developed its masterplan on arsenic reduction by analysing the presence of arsenic in the systems from source to tap. Several measures were put in place to integrate arsenic into water safety planning in order to manage the risks. The underlying cost-benefit study and its implication on water safety planning at Brabant Water is discussed in this presentation.
\end{abstract}

\section{INTRODUCTION}

Drinking water is a major source of inorganic arsenic (As) consumed in EU (EFSA, 2014). The WHO guideline for As in drinking water $(10 \mu \mathrm{g} \mathrm{L}-1)$ is fully met in The Netherlands. The WHO guideline is provisional and therefore every effort should be made to keep the As concentrations as low as reasonably possible in drinking water (WHO, 2006, 2011). In The Netherlands a cost benefit analysis was carried out which revealed that it is advantageous to remove As to $<1 \mu \mathrm{g} \mathrm{L}^{-1}$ (Van der Wens et al., 2016). Brabant Water, the water supply company in the North Brabant Province of The Netherlands integrated the findings in its water safety planning. In this presentation the underlying cost-benefit study and its implication on water safety planning at Brabant Water is discussed.

\section{COST-BENEFIT ANALYSIS}

Figure 1 shows the linearly modelled dose-response relationship which is based on the epidemiological study in Chile and the conclusions of the National Research Council (NRC, 2001) on the increased risk of lung cancer by $41 \%$ due to lifelong exposure to $50 \mu \mathrm{g} \mathrm{L}^{-1}$ As. The relationship led to a calculated health benefit of $10.7 \mathrm{M} €$ per year using the Disability Adjusted Life Years (DALY) method of the National Health Council (NHC, 2007) which is more than twice the calculated annual costs for As removal when the target is set on $1 \mu \mathrm{g} \mathrm{L}^{-1}$ (Van der Wens et al., 2016).

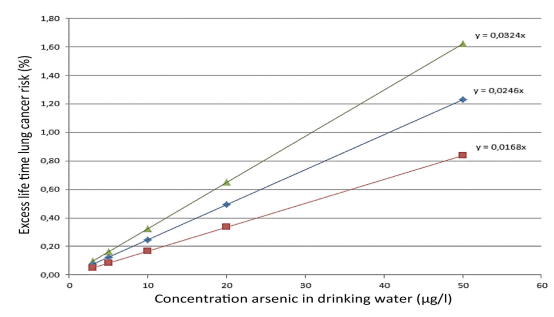

Figure 1. Estimated excess life time lung cancer risk (95\% c.i.) in the Dutch population related to As concentrations in drinking water.

\section{WATER SAFETY PLANNING}

The water safety planning process led to a revision of the water quality policy of Brabant Water (Brabant Water, 2015). Depending on long term investments and relatively slow raw groundwater quality changes an internal set of water quality targets were set. In this way investments were expected to be stable leading to robust treatment works reflecting high quality at low costs. An extensive literature survey was carried out in which three issues were under focus: 1) the high-level health protection of the WHO guideline for borium, 2) the low-level health protection of the WHO guideline for As and 3) the high societal cost benefit ratio of lowering the internal guideline for total hardness.

The second area of results from the water safety planning is insight into the fate of As from source to tap. Figure 2 indicates four issues that will be discussed. The main process for As removal is removal 


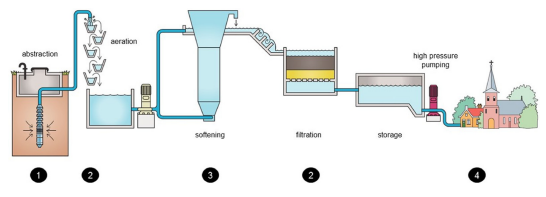

Figure 2. Water safety planning in water treatment.

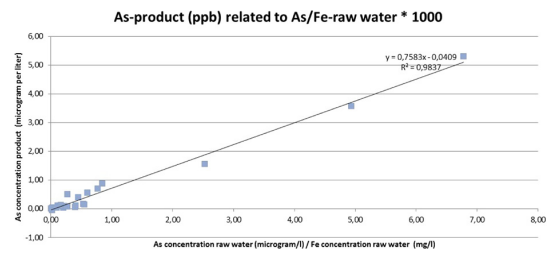

Figure 3. As-product vs As/Fe-ratio for well fields of 30 water treatment plants of Brabant Water.

of iron $(\mathrm{Fe})$ flocs in the filtration process which are laced with sorbed As. The Fe/As ratio and the time for the As(III) to oxidize to As(V) are important factors that determine removal efficiency (Groenendijk, 2016). Implementation of the advanced oxidationcoagulation filtration (AOCF) was done with absence of the softening process. In 2017 the next observations and conclusions were part of the WSP:

1) In Brabant, in the southern part of The Netherlands, severe differences between individual wells occur. These differences are not easy to avoid. Variations in arsenic concentrations from less than $0.1 \mu \mathrm{g} \mathrm{L}^{-1}$ to more than $30 \mu \mathrm{g} \mathrm{L}^{-1}$ may vary within well fields at the same depth (approx. $250 \mathrm{~m}$ deep) at less than hundred meters distance. It seems unavoidable to mix water from wells with high and low concentrations because of the large spatial variation. If the $\mathrm{As} / \mathrm{Fe}$ ratio in the mixed raw water is low enough then As levels will be $<1.0 \mu \mathrm{g} \mathrm{L}^{-1}$. The presence of enough iron appears to be a very important factor. Figure 3 illustrates this linear relationship. For the 30 spatially divided well fields, the average $\mathrm{As} / \mathrm{Fe}$ ratio is plotted against the average As concentration in the drinking water;

2) In the aeration process $\mathrm{As}$ (III) is not oxidized to $\mathrm{As}(\mathrm{V})$. This process can be completed by adding a strong oxidant like permanganate to ensure As(V) occurs as main As species which sorbs better to Fe flocs. This however creates slightly different sludge composition. Although the sludge has good settling conditions, it has poor dewatering characteristics. This may add to financial and environmental costs in the backwash water treatment and sludge removal. Although this appears to be a large factor the cost-benefit ratio remains positive and current research leads to adjustments in the AOCF-process that creates sludge with better dewatering characteristics;

3) At two water treatment locations introducing softening to the process scheme caused elevation of produced drinking water As concentrations. This is caused by the removal of $\mathrm{Fe}$ in the softening reactors. The iron is caught in the $\mathrm{CaCO}_{3}$ pellets. The Fe concentration in the bypass is too low to sorb the residual As. Adding a small amount of Fe is expected to improve As removal;

4) After adjusting the treatment process, it is necessary to clean the distribution network. Although concentrations of dissolved As will not be elevated, the amount of accumulated As in the sediments can cause surge of As. Total As up to 40 times higher than normal dissolved concentrations have been registered during hydraulic disturbances (Blokker et al., 2016).

\section{CONCLUSIONS}

Using the precautionary principle and the modelled dose-effect model of arsenic in drinking water the Dutch water sector aims at reducing As to levels lower than $1.0 \mu \mathrm{g} \mathrm{L}^{-1}$ which are currently 'as low as reasonably possible'. Treatment measures have already been taken and proven to be effective.

The water safety planning process helps to clearly understand of the fate of arsenic though the process from source to tap. Issues form source to tap need to be attended.

\section{ACKNOWLEDGEMENTS}

The authors thank the Dutch Water Companies for their contribution to the policy process and KWR Water research and Brabant Water for the research projects.

\section{REFERENCES}

Blokker, E.J.M., van Vossen, J., Schriks, M., Bosch, J. \& van der Haar, M. 2016. Arsenic accumulation in drinking water distribution networks. In: P. Bhattacharya, M. Vahter, J. Jarsjö, J. Kumpiene, A. Ahmad, C. Sparrenbom, G. Jacks, M.E. Donselaar, J. Bundschuh, \& R. Naidu (Eds.) "Arsenic Research and Global Sustainability As 2016”.CRC Press/Taylor and Francis, pp. 644-645.

Brabant Water 2015. Corporate Water Quality Standards. Internal document. Brabant Water, The Netherlands.

Groenendijk, M. 2016. Removing arsenic to $<1 \mu \mathrm{gL}^{-1}$ in conventional groundwater treatment plants: practical tips and tricks. In: P. Bhattacharya, M. Vahter, J. Jarsjö, J. Kumpiene, A. Ahmad, C. Sparrenbom, G. Jacks, M.E. Donselaar, J. Bundschuh, \& R. Naidu (Eds.) "Arsenic Research and Global Sustainability As 2016”. CRC Press/Taylor and Francis, pp. 519-520.

Van der Wens, P., Baken, K. \& Schriks, M. 2016. Arsenic at low concentrations in Dutch drinking water: assessment of removal costs and health benefits. In: P. Bhattacharya, M. Vahter, J. Jarsjö, J. Kumpiene, A. Ahmad, C. Sparrenbom, G. Jacks, M.E. Donselaar, J. Bundschuh, \& R. Naidu (Eds.) "Arsenic Research and Global Sustainability As 2016”. CRC Press/Taylor and Francis, pp. 563-564.

WHO (World Health Organization) 2006. Water Safety Plan Manual. WHO, Geneva, Switzerland.

WHO (World Health Organization) 2011. Guidelines for Drinking Water Quality, Fourth Edition. WHO, Geneve, Switzerland. 